\title{
Um panorama sobre engajamento escolar: Uma revisão sistemática
}

\section{RESUMO}

O objetivo desse estudo foi revisar sistematicamente as publicações sobre engajamento escolar nas bases SciELO, PsycINFO e ERIC com os seguintes descritores: "school engagement", "engajamento escolar" e "envolvimento escolar". Foram selecionados os estudos que atendiam aos critérios de inclusão: (a) artigos cujos descritores supracitados constavam no título, resumo ou palavras-chave; (b) estudos publicados na modalidade artigo científico e (c) no período de 2014 a 2018. Como critérios de exclusão: (a) artigos com foco em outros temas, (b) não disponíveis na íntegra e (c) duplicados. Foram encontrados 410 estudos e 203 selecionados. A maioria dos estudos é correlacional e a produção sobre engajamento se concentra no eixo América do Norte/Europa. 0 engajamento foi tratado na maioria dos estudos como um constructo tridimensional e foram encontradas 35 escalas que avaliam o engajamento. Faz-se necessário mais estudos experimentais e quasi-experimentais devido à importância destes para a avaliação e desenvolvimento de intervenções que visem melhorar o engajamento escolar e também estudos que avaliem a relação entre o engajamento escolar e outras variáveis pertinentes ao contexto escolar.

Palavras-chave: Engajamento escolar; Envolvimento escolar; Escalas de engajamento.

\section{INTRODUÇÃO}

Um professor à frente de seus alunos percebe alguns olhares atentos e outros distraídos. Como saber quais alunos estão realmente interessados na aula? Quais estão engajados na tarefa? Como estimular o engajamento dos discentes e mantê-los engajados? Como evitar que os alunos evadam da escola? Como fazer com que a experiência de aprendizagem seja de excelência? Estas indagações são comumente feitas por professores, visto que faz parte de sua prática a preocupação com o interesse do aluno e seu desempenho em sala de aula. Dessa forma, o engajamento escolar pode auxiliar os docentes no processo ensino-aprendizagem.

De acordo com Reeve (2012) o engajamento escolar é a extensão do envolvimento ativo de um aluno nas atividades escolares e apresenta quatro
Lygia Vallo e Campos ${ }^{i}$ Universidade Federal de Juiz de Fora, Brasil

Juliana Campos Schmitt ${ }^{i i}$ Universidade Federal de Juiz de Fora, Brasil

Francis Ricardo dos Reis Justi iii Universidade Federal de Juiz de Fora, Brasil 
aspectos distintos, mas altamente inter-relacionados: comportamental, emocional, cognitivo e agente. A dimensão comportamental é relativa ao esforço, à conduta positiva e à participação; a dimensão emocional engloba o interesse, o pertencimento e a atitude positiva em relação à aprendizagem; a dimensão cognitiva é relacionada à autorregulação, às metas de aprendizagem e ao investimento em aprender; e a dimensão agente é relacionada à contribuição intencional, proativa e construtiva dos alunos em relação à instrução recebida, ou seja, é o processo proativo do aluno em tentar criar, aprimorar e personalizar o aprendizado (Reeve, 2012).

A literatura - por exemplo, Christenson et al. (2012) - traz vários modelos para explicar o engajamento escolar. Um dos primeiros é o de Finn (1989), em que o engajamento foi estudado como forma de prevenir o abandono da escola. Para ele, o engajamento contém componentes comportamentais e afetivos, sendo a participação em aula e a adesão às regras exemplos de componentes comportamentais e o pertencimento, a identificação escolar e a valorização da aprendizagem exemplos de componentes afetivos.

Outro modelo é o de Salanova et al. (2000), no qual, inicialmente, o conceito de engajamento foi relacionado ao trabalho, para depois ser expandido para o contexto escolar. Schaufeli, Martínez, et al. (2002) argumentaram que, do ponto de vista psicológico, as tarefas e atividades de um aluno podem ser consideradas análogas às do ambiente de trabalho, pois, como um funcionário, o aluno está envolvido em tarefas e atividades coercivas e estruturadas (p. ex., assistir às aulas, concluir projetos) que são direcionadas a um objetivo específico (p. ex., passar nos exames, conseguir emprego). Desse modo, segundo os autores, o conceito de engajamento relacionado ao trabalho poderia ser estendido ao contexto educacional. Assim, analogamente ao engajamento no trabalho, no modelo de Schaufeli, Salanova, et al. (2002) o engajamento nos estudos é caracterizado por sentimentos de vigor dos alunos, por sua dedicação nos estudos e por sua absorção nas tarefas e atividades, constituindo-se como um polo oposto ao do burnout, que é o sentimento de esgotamento emocional associado a um baixo índice de sentimento de autorrealização (Maslach \& Jackson, 1981). Dessa forma, a partir dos estudos sobre o engajamento na área laboral, Hakanen et al. (2006) e Salanova et al. (2005) começaram a pensar em como o constructo se ajustava ao contexto escolar e quais seriam os correlatos do engajamento de professores e de estudantes.

Na revisão de Fredricks et al. (2004), o engajamento dos alunos na escola foi apresentado como um constructo multidimensional que envolve componentes comportamentais, cognitivos e emocionais. Já Appleton et al. (2008), propuseram quatro dimensões: a acadêmica, a comportamental, a cognitiva e a psicológica. As duas primeiras têm indicadores mais observáveis, ao contrário das demais. No que se refere ao engajamento acadêmico, destaca-se o tempo de tarefa, créditos de disciplina e a realização do dever de casa. A frequência, as suspensões e a participação voluntária em sala e em atividades extraclasse são de cunho comportamental. No que tange ao engajamento cognitivo, este se relaciona com a autorregulação, relevância da escola para o futuro, valor da aprendizagem para atingir objetivos e autonomia; e o engajamento psicológico se refere à identificação, pertencimento e relacionamento. 
Reeve (2012) e Veiga (2013) também propõem uma definição quadripartite, sendo as dimensões propostas: cognitiva, comportamental, emocional e agente. $\mathrm{O}$ engajamento agente resulta na motivação de alta qualidade dos alunos e gera mudanças no ambiente de aprendizagem. Sublinha-se que a dimensão agente do engajamento foi proposta por Reeve e Ching-Mei (2011) devido à incompletude do modelo tripartite do engajamento (Fredricks et al., 2003) que contém somente as dimensões cognitiva, emocional e comportamental. Dessa forma, o modelo tripartite contempla um fluxo educacional linear em que o aluno reage somente à tarefa dada pelo professor, enquanto que o modelo que adiciona o engajamento agente considera as ações dos alunos como um fator de transformação das atividades educacionais (Konold et al., 2018). Assim, o fluxo é cíclico, em que o engajamento influi no contexto, e este modifica o engajamento.

Considerando que aprender e ter sucesso na escola exige engajamento ativo e que o engajamento dos estudantes pode ser um aliado na prevenção de riscos psicossociais e ocupacionais aos quais os estudantes são expostos diariamente (Fredricks et al., 2004), os estudos sobre o engajamento escolar recobrem-se de grande importância. Nesse sentido, mapear a produção sobre o engajamento escolar nos últimos anos é uma forma de detectar as áreas de maior e menor avanço em relação ao tema, constituindo-se, desse modo, em importante contribuição para pesquisas futuras sobre essa relevante temática. Assim sendo, o objetivo geral desse estudo foi entender como o engajamento escolar vem sendo estudado nos últimos cinco anos. Como objetivos específicos procurou-se detectar quais os delineamentos mais frequentemente empregados nos estudos, quais os instrumentos mais utilizados e quais dimensões do constructo foram mais frequentemente mensuradas nas pesquisas. Para tal, realizou-se uma revisão sistemática sobre o tema engajamento escolar, buscando caracterizar a produção internacional e nacional conforme o aspecto metodológico, a temática e a dimensão do engajamento. Sendo assim, buscou-se fornecer um mapeamento acerca do engajamento escolar a fim de verificar se há indicativos de crescimento nessa área de estudo e quais são as suas tendências.

\section{MÉTODO}

Foi realizada uma revisão sistemática da literatura sobre engajamento escolar, por meio de buscas nas bases de dados SciELO, PsycINFO e ERIC, nos meses de fevereiro e março do ano de 2018. Para a busca, o campo palavras-chave foi preenchido com os descritores: "engajamento escolar", "school engagement" e "envolvimento escolar". Foram selecionados os estudos que atendiam aos seguintes critérios de inclusão: (a) artigos cujos descritores supracitados constavam no título, resumo ou palavras-chave; (b) estudos publicados na modalidade artigo científico; e (c) no período de 2014 a 2018. Como critérios de exclusão: (a) artigos com foco em outros temas, (b) não disponíveis na íntegra e (c) repetidos nas bases de dados. 
Foram encontrados 410 estudos, sendo 233 pertencentes à base ERIC, 158 à PsycINFO e 19 à SciELO. Tendo como base a leitura do título, das palavras-chave e do resumo de cada estudo, 373 atenderam aos critérios de inclusão e 52 foram excluídos pelo fato de serem repetidos nas bases de dados. A partir da leitura dos artigos na íntegra, 118 foram excluídos por não terem como foco o estudo do engajamento escolar dos alunos - como exemplo: estudos que se referiam ao envolvimento dos pais na escola (Gavidia-Payne et al., 2015; Rodriguez, \& Elbaum, 2014). Dessa forma, a amostra final resultou em 203 artigos. A Figura 1 sumariza o processo de obtenção dos estudos analisados.

Após a leitura, na íntegra, dos 203 artigos da amostra foram criadas categorias analíticas dos temas que se basearam nas conclusões essenciais das pesquisas, nos objetivos e nas palavras-chave dos estudos. As categorias de análise da literatura utilizadas foram: frequência de artigos por ano e localidade; por tipos de estudo; amostra (segmento escolar e ano escolar); instrumentos de medida; tema e dimensões do engajamento.

Figura 1

Processo de obtenção dos artigos

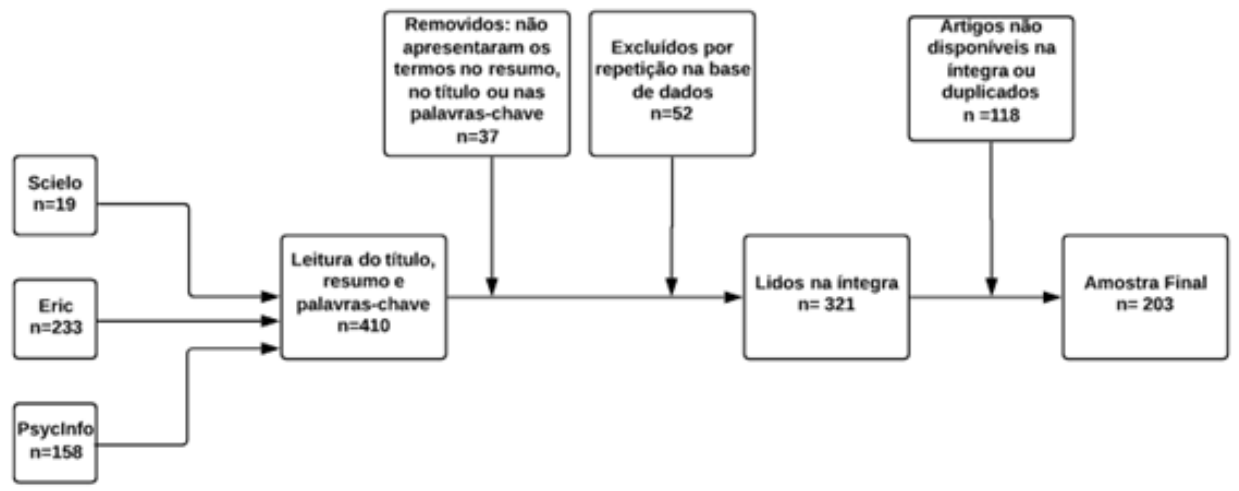

\section{RESULTADOS}

De modo geral, nos anos de 2014 a 2018 observou-se leve crescimento na quantidade de publicações, com pico de produções no ano de 2016 (n=47). Na América do Sul, apesar de poucos artigos, houve um aumento de estudos durante os anos de 2014 a 2018. Já na América do Norte, com a maior concentração dos estudos em relação aos outros continentes ( $\mathrm{n}=88)$, houve um crescimento constante ao longo dos anos, conforme demonstrado na Tabela 1. Destaca-se que houve somente uma produção durante os anos analisados na América Central, sendo esta de 2017. A Ásia e a Europa apresentaram certo crescimento de publicações na área até 2016 e um leve declínio a partir de 2017. Foi observado um número baixo de publicações na Oceania, mas constantes ao longo dos anos. No Brasil não houve publicação de artigos em 2014 e 2017 e o ano com mais publicações foi o de $2018(n=4)$. 
Tabela 1

Frequência dos estudos por ano/localidade

\begin{tabular}{|c|c|c|c|c|c|c|}
\hline & Oceania & $\begin{array}{c}\text { América } \\
\text { Central }\end{array}$ & $\begin{array}{c}\text { América } \\
\text { do Sul }\end{array}$ & $\begin{array}{l}\text { América } \\
\text { do Norte }\end{array}$ & Europa & Asia \\
\hline Ano & Freq. & Freq. & Freq. & Freq. & Freq. & Freq. \\
\hline 2014 & 2 & 0 & 0 & 18 & 14 & 4 \\
\hline 2015 & 4 & 0 & 1 & 16 & 9 & 5 \\
\hline 2016 & 2 & 0 & 3 & 16 & 17 & 9 \\
\hline 2017 & 3 & 1 & 0 & 16 & 13 & 8 \\
\hline 2018 & 2 & 0 & 4 & 22 & 11 & 3 \\
\hline
\end{tabular}

Em relação aos tipos de estudo, os correlacionais foram predominantes, com 164 artigos (81\%) adotando este delineamento. Os estudos quasi-experimentais ocuparam o segundo lugar em frequência, com 14 estudos. Com quatro artigos, as pesquisas psicométricas ficaram em terceiro lugar, conforme a Tabela 2. Nota-se um número bastante inferior de estudos quasi-experimentais e psicométricos em comparação ao número de estudos correlacionais.

Tabela 2

Frequência dos estudos por tipos de estudo

\begin{tabular}{lcc}
\hline \multicolumn{1}{r}{ Típos de estudo } & Frequéncia & $\%$ \\
\hline Correlacional & 164 & 80,8 \\
Quasi-Experimental & 14 & 6,9 \\
Estudos psicométricos & 4 & 2 \\
Revisão narrativa & 2 & 1 \\
Revisão sistemática & 1 & 0,5 \\
Observacional & 1 & 0,5 \\
Grupo focal & 5 & 2,5 \\
Entrevista & 5 & 2,5 \\
Teoria fundamentada & 3 & 1,4 \\
Artigo teórico & 3 & 1,4 \\
Estudo etnográfico & 1 & 0,5 \\
\hline
\end{tabular}

No que diz respeito à amostra, destacam-se o segmento escolar e ano escolar. Para a análise do segmento escolar observou-se a idade média dos participantes nos estudos, sendo então convertida a idade média para as nomenclaturas dos segmentos educacionais do Brasil ${ }^{1}$. Sendo assim, a predominância dos estudos foi no ensino fundamental, com mais da metade dos estudos neste segmento. Os anos finais do ensino fundamental, que compreendem do $6^{0}$ ao $9^{\circ}$ ano, foram os que concentraram a maioria dos estudos, como demonstrado na Tabela 3. Outro ponto a se destacar é a baixa frequência de estudos nos anos iniciais do ensino fundamental ( $1^{\circ}$ ano ao $5^{\circ} \mathrm{o}$ ano), sendo o 5 o ano o que tem o maior número de estudos $(n=17)$ desse segmento, conforme demonstrado na Figura 2. Já nos anos finais do ensino fundamental, a diferença na quantidade dos estudos entre o $6^{\circ}$ ano $(n=29)$ e o $7^{\circ}$ ano $(n=51)$ foi significativa, evidenciando um maior interesse em investigar o engajamento escolar em alunos mais velhos.

1. Educação infantil: crianças de 0 a 6 anos; anos iniciais do ensino fundamental: crianças de 6 a 12 anos; anos finais do ensino fundamental: crianças e jovens de 12 a 15 anos; ensino médio: adolescentes de 15 a 18 anos.e ensino superior: a partir de 18 anos após concluir 0 ensino médio. 
Tabela 3

Frequência dos estudos por segmento escolar

\begin{tabular}{lc}
\hline \multicolumn{1}{c}{ Segmento escolar } & Frequência \\
\hline Educação Infantil (0 a 6 anos) & 12 \\
Ensino Fundamental Anos Iniciais (6 a 12 anos) & 27 \\
Ensino Fundamental Anos Finais (12 a 15 anos) & 110 \\
Ensino Médio (15 a 18 anos) & 78 \\
Ensino Superior (acima de 18 anos) & 6 \\
\hline
\end{tabular}

Figura 2

Frequência dos estudos por ano escolar

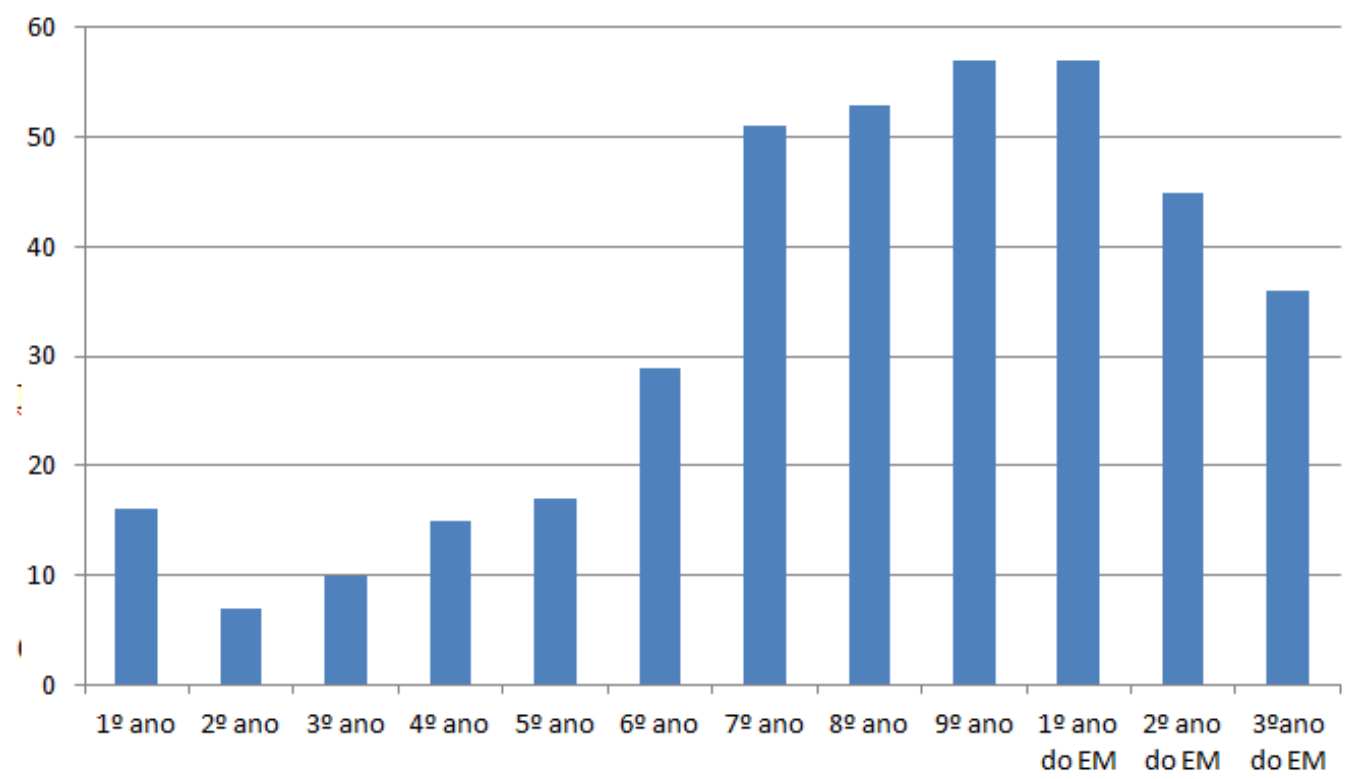

No que se refere aos instrumentos de medida, foram encontradas 35 escalas, dentre elas 17 originais e 18 adaptadas. As escalas utilizadas com mais frequência foram, respectivamente, "School Engagement Scale" (SES), de Fredricks, Blumenfeld, Friedel e Paris (2005) (n=9), "The School Engagement Instrument" (SEI), de Appleton, Christenson, Kim, e Reschly (2006) ( $\mathrm{n}=8$ ), e "Utrecht School Engagement Scale" (UWES), de Schaufeli, Salanova, et al. (2002). A Tabela 4 mostra todas as escalas encontradas com as dimensões analisadas e o segmento escolar em que foram aplicadas. Alguns estudos analisados utilizaram instrumentos que mediam outros constructos correlatos, como o estudo de Voisin, Elsaesser, Kim, Patel, e Cantara (2016), que fez uso de itens modificados da "School Bonding Scale" (Fleming et al., 2010) para mensurar o engajamento. Salienta-se que prevaleceram as escalas em que o público-alvo era dos anos finais do ensino fundamental $(n=24)$ e do ensino médio $(n=19)$. A educação infantil foi a que obteve a menor frequência de estudos com escala $(n=2)$, sendo que uma das escalas foi utilizada para mensurar o engajamento na educação infantil até ao ensino médio. Os anos iniciais do ensino fundamental e o ensino superior também apresentaram baixa frequência de estudos com escala - quatro e três estudos, respectivamente. Das quatro escalas dos anos iniciais do ensino fundamental, três foram utilizadas 
para medir o constructo em outro segmento escolar além dos anos iniciais do ensino fundamental, o que também ocorreu com as escalas do ensino superior.

Tabela 4

Escalas de engajamento escolar

\begin{tabular}{|c|c|c|}
\hline Escala & Freq. & Segmento escolar \\
\hline $\begin{array}{l}\text { Teacher-rated Effortful Engagement (TREE) por Hughes } \\
\text { e Kwok (2006) }\end{array}$ & 1 & Ed. infantil \\
\hline $\begin{array}{l}\text { School Engagement Questionnaire por Furrer e Skinner } \\
\qquad(2003)\end{array}$ & 4 & Ens. fund. anos iniciais \\
\hline School Engagement Scale por Can (2008) & 1 & Ens. fund. anos iniciais \\
\hline $\begin{array}{l}\text { The School Engagement Instrument (SEI) por Appleton et } \\
\qquad \text { al. (2006) }\end{array}$ & 8 & $\begin{array}{l}\text { Ens. fund. anos } \\
\text { iniciais, ens. fund. } \\
\text { anos finais, ensino } \\
\text { médio e superior }\end{array}$ \\
\hline $\begin{array}{l}\text { Delaware Student Engagement Scale (DSES) por Bear et } \\
\text { al. (2016) }\end{array}$ & 2 & $\begin{array}{l}\text { Ens. fund. anos } \\
\text { iniciais, ens. fund. } \\
\text { anos finais, ensino } \\
\text { médio e superior }\end{array}$ \\
\hline School Engagement Scale por Finn e Rock (1997) & 1 & Ens. fund. anos finais \\
\hline The Gallup Student Poll on Engagement (GSPE) ${ }^{a}$ & 1 & Ens. fund. anos finais \\
\hline School Engagement Scale por Zhang et al (2011) & 1 & Ens. fund. anos finais \\
\hline School Engagement Scale por Brutsaert (1993) & 2 & Ens. fund. anos finais \\
\hline
\end{tabular}

Mobilisation/démobilisation Scolaire por Hemandez (2012)

Wellbom Engagement Scale por Skinner, ZimmerGembeck, Connell, Eccles e Wellbom (1998).

Inquérito Acerca do Envolvimento dos Estudantes na Escola (IEEE) por Rola (2012)

Questionánio de Envolvimento dos Alunos na Escola (EAE - E4D) por Veiga (2013)

School Engagement por Hidiroğlu (2014)

EAE-E4D Scale-brazilian Adaptation de Veiga (2013) por Silveira e Justi (2018)

School Engagement Scale de Fredricks, Blumenfeld, Friedel e Paris (2005) por Çengel, Totane Çögmen (2017)

School Engagement Measure (SEM) de Fredricks et al. (2005) por Yusof, Ang e Oei (2017)

Utrecht School Engagement Scale (UWES) por Schaufeli, Salanova, et al. (2002)

Scale for School Engagement por Arastaman (2006)

Engagement versus Disaffection with Leaming Scale por Skinner et al. (2008)

School Engagement Scale, por Fredricks et al. (2005)

Schoolwork Engagement Inventory (EDA) por SalmelaAro e Upadyaya (2012).
Ens. fund. anos finais

Ens. fund. anos finais

Ens. fund. anos finais

Ens. fund. anos finais

Ens. fund. anos finais

Ens. fund. anos finais

Ens. fund. anos finais

Ens. fund. anos finais

Ens. fund. anos finais, ensino médio e superior

Ens. fund. anos finais, ensino médio e superior

Ens. fund. anos finais $e$ ensino médio

Ens. fund. anos finais $\mathrm{e}$ ensino médio

Ens. fund. anos finais $\mathrm{e}$ ensino médio

Dimensões

Acadêmico,

comportamental, cognitivo e psicológico

Emocional e comportamental

Emocional, cognitivo e comportamental

Cognitivo e psicológico

Emocional,cognitivo e comportamental

Emocional, cognitivo e comportamental

Engajamento/desengajamen to

Emocional, cognitivo e comportamental

Emocional, cognitivo e comportamental

Autoavaliação do curso escolar, conduta em sala de aula, perseverança e interesse em trabalho pessoal e sucesso

Comportamental e emocional

Emocional, cognitivo e comportamental

Agente, cognitivo, comportamental e emocional

Agente, cognitivo, comportamental e emocional

Agente, cognitivo, comportamental e emocional

Emocional, cognitivo e comportamental

Comportamental e emocional

Emocional, cognitivo e comportamental

Emocional, cognitivo e comportamental

Emocional e comportamental

Emocional, cognitivo e comportamental

Vigor, dedicação e absorção 
Behavioral-emotional-cognitive School Engagement Scale (BEC-SES) por Li e Lemer (2013)

School Engagement Scale da National Center for School Engagement $(\mathrm{NCSE})^{b}$

The School Engagement Measure por Wang, Willett, e Eccles (2011)

Adaptation UWES de Schaufeli, Salanova, et al. (2002) por Gouveia (2009)

School Engagement Scale for Children and Adolescents (High School Form) por Çakar e Karataş (2014)

Spanish Version School Engagement Measure (SEM) de Fredricks et al. (2005) por Ramos-Díaz, RodríguezFemández e Revuelta (2016)

School Engagement scale de por Uzzaman \& Karim (2016)

Agentic Engagement Scale por Mameli e Passini (2017)

Brazilian Delaware Student Engagement Scalebrazilian DSES por Holst, Weber, Bear, e Lisboa (2016)

New York City Social and Academic Engagement Study (NYCASES) $^{c}$

School Engagement Scale por Awang-Hashim, Azlina e Sani (2008)

Student School Engagement Measure (SSEM) por Hazel et al. (2013)

School Engagement Subscale of the Drug Free Schools Outcome Study Questions

$$
\text { ensino médio }
$$

Ens. fund. anos finais

Ens. fund. anos finais ensino médio

Ens. fund. anos finais $e$ ensino médio

Ens. fund. anos finais $\mathrm{e}$ ensino médio

Ens. fund. anos finais e ensino médio

Ens. fund. anos finais ensino médio

Ensino médio

Ensino médio

Ensino médio

Ensino médio

Ensino médio

Ensino médio

Utilizado fora do contexto

escolar
Emocional, cognitivo e comportamental

Emocional, cognitivo e comportamental

Emocional, cognitivo e comportamental

Vigor, dedicação e absorção

Envolvimento com a escola, envolvimento com os professores, envolvimento com os amigos

Emocional, cognitivo e comportamental

\section{Emocional, cognitivo e} comportamental

Agente, cognitivo, comportamental e emocional

\section{Cognitivo/comportamental} e emocional

Emocional, cognitivo e comportamental

Cognitivo, comportamental e psicológico

Aspiração, pertencimento, produtividade

Não informado

Nota . Ed. infantil = educação infantil; ens. fund. anos iniciais = ensino fundamental anos iniciais; ens. fund. anos finais = ensino fundamental anos finais.

a A escala Gallup Student Poll on Engagement é uma escala desenvolvida para um programa de consultoria e pesquisa da Gallup e pode ser encontrada no endereço https://www.gallup.com/education/.

b A School Engagement Scale da National Center for School Engagement é uma subescala do programa School Policy Improvement e pode ser encontrada no endereço http://schoolengagement.org/school-engagement-services/school-policyreform

"A New York City Social and Academic Engagement Study é uma escala desenvolvida para um levantamento de dados financiado pela New York University Challenge Grant e pode ser encontrada no endereço https://wp.nyu.edu/sinin/2016/07/19/nycases

Devido à importância de instrumentos de medida com dados psicométricos para o desenvolvimento de pesquisas na área, optou-se por destacar e descrever a seguir as três escalas mais frequentemente utilizadas nos estudos incluídos nessa revisão sistemática. A escala mais utilizada foi a SES, de Fredricks et al. (2005). Essa escala de 19 itens avalia o engajamento cognitivo, comportamental e emocional em alunos do ensino fundamental. Em sua construção foram extraídos itens de outros instrumentos que avaliam o engajamento e redigidos novos itens em escala Likert de 1 a 5 ( $1=$ never, $5=$ all of the time; or 1 = not at all true, $5=$ very true; 1 = nunca, $5=$ o tempo todo; ou 1 = nada verdadeiro, 5 = muito verdadeiro). A dimensão comportamental foi composta por cinco itens (por exemplo, "I follow the rules at school"; "Eu sigo as regras da escola"), a dimensão emocional foi constituída por seis itens (por exemplo, "I like being at school"; "Eu gosto de estar na escola") e a dimensão cognitiva por oito itens (por exemplo, "I check my schoolwork for mistakes"; 
"Eu verifico minhas tarefas escolares à procura de erros"). A validação da escala contou com duas ondas, sendo que houve modificações nos itens de engajamento cognitivo na segunda onda devido à baixa confiabilidade apresentada. Na primeira onda participaram 661 crianças (238 alunos do $4^{\circ}$ ano, 205 do $5^{\circ}$ ano e 218 do $6^{\circ}$ ano) e na segunda 294 ( 151 do $5^{\circ}$ ano e 143 do $6^{\circ}$ ano). Na segunda onda, o $4^{\circ}$ ano não foi incluído na amostra, pois segundo Fredricks et al. (2005) a não inclusão deste ano no estudo aumentaria o índice de confiabilidade dos itens de engajamento cognitivo. Além do engajamento, o estudo incluiu medidas de percepção do contexto social (apoio do professor e apoio de pares), percepção do contexto acadêmico (desafio da tarefa e orientação para o trabalho), competência, valor e apego escolar. Ressalta-se que juntamente com a escala do engajamento dos alunos foi administrada uma escala de engajamento preenchida pelos professores com os itens inspirados na escala dos alunos. As correlações entre engajamento e medidas de apego e valor escolar foram significativas, sendo moderadamente correlacionados os tipos de engajamento com o apego escolar ( $r=.44$ a .57) e correlacionados de forma mais fraca com a percepção do valor da escola $(r=.26$ a .32). Os relatos do engajamento escolar dos alunos foram mais fortemente correlacionados com os relatos de comportamento dos professores ( $r=.29$ a .43) do que com as percepções de emoção dos professores $(r=.15$ a .20$)$. A análise fatorial exploratória demonstrou três fatores e uma consistência interna variando de .77 ('engajamento comportamental') a .86 ('engajamento emocional').

A segunda escala mais utilizada foi a SEI, de Appleton et al. (2006). Essa escala de autorrelato mede o engajamento cognitivo/psicológico dos estudantes. Validada com uma amostra de 1931 alunos do 9o ano. 0 instrumento-piloto foi construído com base em uma revisão de literatura, cujos descritores foram: engajamento, participação, identificação com a escola, autorregulação, engajamento acadêmico, engajamento comportamental, engajamento cognitivo e engajamento psicológico. 0 instrumento-piloto foi aplicado em 31 alunos do 8. ano para avaliar a clareza, a compreensão e a relevância percebida dos itens. A versão-piloto do SEI continha 30 itens destinados a medir os níveis de engajamento cognitivo (por exemplo, relevância percebida da escola) e 26 itens destinados a examinar o envolvimento psicológico (por exemplo, conexão percebida com outros na escola). Seis itens reversos foram posicionados intermitentemente aos outros itens. Após a aplicação da escala nos estudantes, foi realizada análise fatorial exploratória e os itens com carga fatorial inferior a .40 foram excluídos. Foi realizada uma análise fatorial confirmatória em que o modelo de cinco e o de seis fatores se aproximaram da faixa de ajuste aceitável, enquanto que o modelo de quatro fatores se diferiu substancialmente. Para determinar o melhor ajuste entre os modelos de cinco e seis fatores, as estatísticas de mudança foram consultadas. 0 teste da diferença do qui-quadrado foi significante, sugerindo a importância do sexto fator. Os seis fatores encontrados e as respectivas confiabilidades dos itens foram: Fator 1 ('Relacionamentos Professor-Aluno', $\alpha=.88$ ), Fator 2 ('Controle e Relevância do Trabalho Escolar', $\alpha=.80$ ), Fator 3 ('Apoio dos Pares para Aprendizagem', $\alpha=.82$ ), Fator 4 ('Aspirações e Metas Futuras', $\alpha=.78$ ), Fator 5 ('Apoio da Família para Aprendizagem', $\alpha=.76$ ) e Fator 6 ('Extrínsecos Motivação', $\alpha=.72$ ). 
Por fim, outra escala utilizada foi a UWES, de Schaufeli, Salanova, et al. (2002). Composta de 24 itens, inicialmente projetada para o contexto de trabalho, essa escala foi adaptada para o contexto escolar. Para isto foi utilizada uma amostra de 1661 estudantes universitários de três países: Espanha $(n=623)$, Portugal $(n=727)$ e Holanda $(n=311)$. Os itens da UWES que se referem ao trabalho foram substituídos por itens relacionados a estudos ou a aulas. Dessa forma, a escala contou com 17 itens que foram divididos em três subescalas: 'Vigor' (seis itens; como exemplo: "When I study, I feel like I am bursting with energy"; "Quando eu estudo, sinto que estou cheio de energia"), 'Dedicação' (cinco itens; por exemplo, "I find my studies to be full of meaning and purpose"; "Eu acho que meus estudos são cheios de significado e propósito") e 'Absorção' (seis itens; por exemplo, "Time flies when I'm studying"; "O tempo voa quando eu estou estudando"). A escala é do tipo Likert de 7 pontos $(0$ (never) to 6 (always); 0 (nunca) até 6 (sempre)). A confiabilidade da escala foi analisada por meio da análise da consistência interna utilizando o coeficiente de confiabilidade alfa de Cronbach, e a validade por meio de análise fatorial confirmatória na qual foram testados os modelos de três e de um fator, além da relação entre o engajamento e o burnout. A consistência interna para cada subescala foi a seguinte: 'vigor' ( $\alpha=.87)$, 'dedicação' $(\alpha=.85)$ e 'absorção' $(\alpha=.92)$. Os índices de ajuste do modelo de três fatores foram melhores do que o de um fator. A escala de engajamento e a escala de burnout foram negativamente correlacionadas, demonstrando que os constructos diferem entre si.

Outro assunto de interesse são os temas mais investigados nos estudos. A partir da leitura dos artigos foram criadas 36 categorias temáticas. Vale destacar que $40 \%$ dos estudos foram classificados em dois temas: i) suporte dos pais, professores e pares $(n=61)$, como ocorre em Portilla et al. (2014), que investigaram a relação entre a autorregulação, a qualidade do relacionamento professor-criança e o engajamento escolar na previsão da competência acadêmica; ii) saúde mental $(n=20)$, como em Marques, Lopez, Fontaine, Coimbra, e Mitchell (2015), que avaliaram a relação entre os níveis de satisfação com a vida durante a infância, os problemas de saúde mental e o engajamento escolar. Na Tabela 5 encontram-se os temas que obtiveram as maiores frequências e suas descrições. 
Tabela 4

Frequência de Estudos por Tema

\begin{tabular}{|c|c|c|c|}
\hline Tema & Descriçåo & Freq. & $\%$ \\
\hline $\begin{array}{l}\text { Suporte dos pais, } \\
\text { professores e pares }\end{array}$ & $\begin{array}{c}\text { Estudos que envolvemestilos parentais, situação de divórcio, particịação dos } \\
\text { pais nas escolas, popularidade entre os pares, relação de amizade, autoeficácia } \\
\text { parental e julgamento dos profess ores. }\end{array}$ & 61 & $30 \%$ \\
\hline Saúde Mental & $\begin{array}{c}\text { Estudos que envolvem bem-estar psicológico, alunos com depressão, } \\
\text { ansiedade, bumout, terapias e vicios. }\end{array}$ & 20 & $10 \%$ \\
\hline $\begin{array}{l}\text { Estudantes de } \\
\text { minorias étnicas e } \\
\text { raciais }\end{array}$ & $\begin{array}{l}\text { Estudos relacionados a minorias como ciganos, bem como a percepção da } \\
\text { discriminação e justiça racial. }\end{array}$ & 17 & $8 \%$ \\
\hline $\begin{array}{l}\text { Desempenho } \\
\text { Acadêmico }\end{array}$ & $\begin{array}{l}\text { Estudos que envolvemnotas escolares, aprovação, faculdade, capacidade de } \\
\text { leitura e habilidades cognitivas. }\end{array}$ & 16 & $7 \%$ \\
\hline $\begin{array}{l}\text { Aspectos } \\
\text { Contextuais }\end{array}$ & $\begin{array}{l}\text { Estudos que envolvem clima escolar, qualidade da sala de aula, clima de } \\
\text { aprendizagem, segurança da escola e uso de tecnologia da informação. }\end{array}$ & 11 & $5 \%$ \\
\hline Percepção escolar & $\begin{array}{l}\text { Estudos que envolvem a percepção dos alunos em relação à escola e as } \\
\text { percepções dos estudantes sobre a estrutura de objetivos da escola. }\end{array}$ & 6 & $3 \%$ \\
\hline Agressividade & $\begin{array}{l}\text { Estudos que tratam sobre delinquência, violência, agressividade, contextos } \\
\text { violentos e maus-tratos. }\end{array}$ & 6 & $3 \%$ \\
\hline $\begin{array}{l}\text { Necessidades } \\
\text { Especiais }\end{array}$ & $\begin{array}{c}\text { Estudos que envolvem alunos com necessidades especiais mentais, fisicas, } \\
\text { alunos com alta dotação, TDAH e doenças crônicas. }\end{array}$ & 6 & $3 \%$ \\
\hline Metodologia & $\begin{array}{l}\text { Estudos que tratam sobre metodologias diferenciadas e novas práticas } \\
\text { pedagógicas. }\end{array}$ & 5 & $3 \%$ \\
\hline $\begin{array}{l}\text { Inter-relação entre } \\
\text { as dimensões }\end{array}$ & $\begin{array}{l}\text { Estudos que investigam a multidimensionalidade do constructo, que fazem } \\
\text { comparação entre os conceitos e dimensões em diferentes paises. }\end{array}$ & 5 & $3 \%$ \\
\hline Gênero e LGBT & $\begin{array}{l}\text { Estudos que investigam a masculinidade, os papéis dos gêneros e a relação } \\
\text { LGBT com o engajamento. }\end{array}$ & 4 & $2 \%$ \\
\hline Imigrantes & Envolvem alunos imigrantes ou filhos de imigrantes. & 4 & $2 \%$ \\
\hline Bullying & Estudos relacionados à vitimização entre pares & 4 & $2 \%$ \\
\hline Outros & $\begin{array}{l}\text { Estudos com temáticas diversas como resiliência, atividades extracurriculares, } \\
\text { apego, gratidão e de disciplinas escolares. }\end{array}$ & 38 & $19 \%$ \\
\hline
\end{tabular}

Em relação às dimensões do engajamento escolar, foram 186 os estudos que as relataram. Dentre eles, $67 \%$ consideraram o constructo tridimensional $(n=126)$. Salienta-se que a concepção tripartite constituída por engajamento cognitivo, engajamento comportamental e engajamento emocional foi a que, dentre os 126 estudos, obteve a frequência mais alta $(n=112)$. A segunda com maior frequência nos 186 estudos foi a concepção do engajamento com uma só dimensão ( $n=13)$, e a concepção quadridimensional teve a terceira maior frequência $(n=12)$. Estes dados revelam a principal postura científica da área do engajamento escolar: predomínio em abordar o engajamento como um constructo multidimensional, definido pelas dimensões cognitiva, emocional e comportamental.

\section{DISCUSSÃO}

A partir desta revisão foi possível observar que as publicações referentes ao engajamento escolar têm sofrido um leve crescimento ao longo dos anos, levando-se ao entendimento de que o engajamento é um tema particularmente interessante para aqueles que buscam estudar o contexto escolar. No Brasil, o estudo sobre o tema ainda é incipiente, visto que foram encontrados nessa 
revisão apenas sete artigos sobre o tema compreendendo os anos de 2014 a 2018 (Coelho \& Dell'Aglio, 2018; Fonsêca et al., 2016; Rodrigues \& Nascimento, 2016; Silveira \& Justi, 2018; Stelko-Pereira \& Williams, 2016; Valle et al., 2018; Valle et al., 2015), o que evidencia uma baixa frequência de publicação sobre o tema. Torna-se difícil compreender isto, visto que o constructo é tratado na literatura como um dos melhores preditores do abandono escolar (p. ex., Fredricks et al., 2004; Lovelace et al., 2018) e também é importante para o sucesso escolar (p. ex., Baker et al., 2018). É possível que esse pequeno número de estudos sobre o tema no Brasil se deva ao número reduzido de instrumentos para avaliar o engajamento escolar desenvolvidos ou adaptados ao contexto brasileiro. De fato, foi encontrado, nessa revisão, somente o estudo de Silveira e Justi (2018), dos sete estudos citados. Os autores referidos adaptaram um instrumento de medida para avaliar o engajamento escolar; apesar de a escala Brazilian Delaware Student Engagement Scale-Brazilian/ DSES (Holst et al., 2016) ter sido utilizada na pesquisa de Coelho e Dell'Aglio (2018) como instrumento de medida, o estudo de adaptação dessa escala não foi encontrado, durante essa revisão, dentro das bases de dados contempladas. Tendo em vista o panorama internacional, em especial a América do Norte e a Europa, percebe-se considerável diferença no que se refere ao número de publicações em relação ao Brasil. Além de isso indicar um maior avanço na pesquisa acerca do tema, já que existem nesses países instrumentos com dados psicométricos desenvolvidos há mais tempo (como, p. ex., a SES, de Fredricks et al. (2005), a SEI, de Appleton et al. (2006) e a UWES, de Schaufeli, Salanova et al. (2002); Veiga, 2013), também há que se destacar que existem programas que incentivam e procuram avaliar o engajamento escolar em larga escala, como é o caso do National Center for School Engagement (NCSE) nos Estados Unidos, que colabora com distritos escolares, agências de aplicação da lei, tribunais e agências estaduais e federais promovendo o engajamento em estudantes e fomentando pesquisas em relação ao engajamento escolar dos alunos.

No que se refere à amostra, os estudos encontrados nessa revisão sistemática se concentraram nos anos finais do ensino fundamental $(n=110)$, seguido do ensino médio $(n=78)$, sendo que alguns estudos $(n=44)$ contemplaram ambos os segmentos. Acredita-se que a escolha de pesquisar o engajamento escolar em crianças mais velhas e adolescentes pode ser explicada pelo próprio motivo que deu origem ao engajamento escolar: a prevenção do abandono da escola acrescido do recente interesse na relação entre o engajamento e o desempenho acadêmico. É na faixa etária que contempla os anos finais do ensino fundamental e ensino médio (12-18 anos) que a preocupação com o desempenho acadêmico se intensifica e há o aumento do abandono escolar (Upadyaya \& Salmela-Aro, 2013). Além disso, é notório que a maioria dos estudos dessa revisão sistemática é correlacional $(\mathrm{n}=182)$. Esse fato pode indicar que os pesquisadores ainda não têm clareza de como intervir diretamente no engajamento escolar de forma a planejar estudos experimentais ou quasi-experimentais. No entanto, embora seja compreensível, pelos motivos discutidos acima, que a maioria das pesquisas desenvolvidas sejam correlacionais e com crianças mais velhas, essa conjunção de fatores culmina em sérios problemas quando os pesquisadores fazem inferências sobre a direção da relação entre o engajamento escolar e o desempenho acadêmico. 
Uma ilustração dessa situação pode ser obtida pela discussão dos estudos sobre engajamento escolar e leitura (p. ex., Choet al., 2018; Guo et al., 2015; Kim et al., 2017; Zhao et al., 2019).

Em um estudo publicado recentemente, Cho et al. (2018) investigaram a relação entre motivação (mindset), engajamento (engajamentos comportamental, cognitivo e emocional, que foram derivados de escalas de competência acadêmica e de autoconceito) e compreensão de leitura em alunos com dificuldade de leitura do $4^{\circ}$ e $5^{\circ}$ anos escolares nos Estados Unidos (crianças de 10 e 11 anos). Os autores supracitados observaram que mesmo após o controle da habilidade de decodificação e do vocabulário, o engajamento emocional contribuiu para a compreensão de leitura e mediou a relação da motivação (mindset) com a compreensão. Apesar de não ser um estudo longitudinal, Cho et al. (2018) assumiram que foi o engajamento emocional que contribuiu para a compreensão e não o contrário. 0 mesmo tipo de inferência pode ser notada no estudo de Zhao et al. (2019) que avaliou a relação entre suporte dos professores (percepção dos estudantes), autoconceito acadêmico (escala de autorrelato), interesse na leitura (derivado de itens do PISA) e engajamento na leitura (derivado de itens do PISA) em crianças de 8 a 13 anos. Observou-se no estudo que o suporte dos professores teve um efeito no interesse na leitura que foi mediado pelo autoconceito acadêmico. Apesar de não avaliarem diretamente o desempenho em leitura (precisão, fluência e compreensão de leitura), os autores inferiram que o suporte percebido dos professores leva a um maior engajamento e que isso levaria a uma melhor leitura. No entanto, por se tratar de um estudo transversal, esse tipo de inferência é difícil de se sustentar, já que é logicamente possível imaginar o oposto, que o desempenho leva a um maior engajamento.

Para melhor entender a relação entre engajamento e desempenho acadêmico faz-se necessário cada vez mais estudos longitudinais, experimentais e quasi-experimentais. Nesse sentido, dois estudos que podem contribuir para o debate são os de Guo et al. (2015) e Kim et al. (2017). Kim et al. (2017)

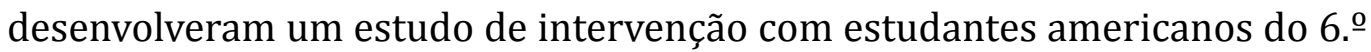
ao 8. ${ }^{\circ}$ anos com dificuldade de leitura. 0 grupo experimental participou de um programa suplementar para desenvolver a leitura que envolvia técnicas para melhorar a decodificação, o vocabulário, a compreensão e o engajamento em leitura. Nos resultados observou-se que os estudantes com maior engajamento comportamental apresentaram maiores efeitos do treinamento e que os engajamentos emocional e cognitivo contribuíram para explicar a variância adicional nos dados. Por ser um estudo experimental, o estudo de Kim et al. (2017) representa um avanço em relação a outros estudos que fazem inferências sobre a direção da relação entre engajamento e desempenho. No entanto, um dos problemas desse estudo é que, como a intervenção se focou em diversos fatores (decodificação, vocabulário, compreensão, etc.) e não apenas no engajamento em relação à leitura, a existência de um efeito da intervenção não constitui evidência inequívoca de um efeito do engajamento sobre o desempenho. Por fim, dificultando ainda mais a ideia de uma relação unívoca na qual o engajamento leva a um melhor desempenho em leitura. É importante considerar que, em um estudo longitudinal, Guo et al. (2015) desenvolveram análises de correlação com defasagem cruzada entre 
o desempenho em leitura e o engajamento comportamental em um grupo de crianças, incluindo os $1^{\circ}$ e $3^{\circ}$ anos da escola elementar e depois o $3^{\circ}$ e $5^{\circ}$ anos. Nas análises realizadas por Guo et al. (2015), observou-se que foi a habilidade de leitura que predisse o engajamento comportamental e não o contrário, em ambos os períodos de tempo considerados, resultado esse que se contrapõe à interpretação observada nos outros estudos da relação entre engajamento e desempenho (Cho et al., 2018; Kim et al., 2017; Zhao et al., 2019).

Por fim, é importante considerar que o objetivo de se discutir a relação entre engajamento escolar e desempenho em leitura não foi criticar alguns desses estudos em particular, mas sim ilustrar com mais detalhes um problema potencial na área que se detectou na presente revisão sistemática. Esse problema decorre de um número grande de estudos correlacionais/ transversais desenvolvidos com crianças em etapas já avançadas da vida escolar (como o final do ensino fundamental e o ensino médio), em que se infere, muitas vezes, uma relação direta do engajamento escolar para o desempenho acadêmico. No entanto, ao se considerar, em pormenor, os estudos que avaliaram a relação entre engajamento e desempenho em leitura, percebe-se que muitas vezes essa inferência é difícil de se sustentar, por mais intuitiva que possa parecer em uma primeira análise. Além disso, como pontuam Justi et al. (2019), é importante considerar que é possível que a relação entre o engajamento escolar e o desempenho acadêmico mude ao longo do tempo. Nos anos iniciais, quando as habilidades elementares de leitura estão sendo estabelecidas, é possível que a relação seja do desempenho em leitura para o engajamento (como, p. ex., no estudo de Guo et al., 2015), mas, nos anos mais avançados, com a automatização plena das habilidades elementares de leitura, que a relação passe a ser do engajamento para o desempenho (como, p. ex., no estudo de Kim et al., 2017). É importante enfatizar que as pesquisas sobre o engajamento escolar pretendem avançar no estudo da relação entre engajamento e desempenho; é importante que o número de estudos longitudinais e experimentais sobre a temática aumente consideravelmente e que, além disso, mais pesquisas sejam desenvolvidas sobre o engajamento escolar em crianças nos anos iniciais de escolarização.

Outro ponto que merece destaque nessa revisão são os instrumentos utilizados para se avaliar o engajamento escolar. Das 35 escalas encontradas nessa revisão sistemática, 34 eram de autorrelato. Um dos motivos para tal fato é que a maioria das escalas é para alunos dos anos finais do ensino fundamental e do ensino médio que são capazes de preenchê-las sem muitas dificuldades. Ao mesmo tempo em que esse fato explica a concentração de estudos nessa faixa etária, conforme discutido acima, isso leva a limitações no estudo longitudinal da relação entre engajamento e desempenho, sendo necessário que sejam desenvolvidos instrumentos que não envolvam autorrelato por serem mais fáceis de se aplicar em crianças mais novas. Além disso, sobre as escalas de engajamento é importante destacar que aproximadamente $43 \%$ dos estudos $(n=88)$ utilizaram escalas que avaliam constructos correlatos para mensurar o engajamento escolar. Como exemplo, cita-se a pesquisa de Wang et al. (2015), que utilizou a "School Value Scale" (Eccles et al., 1993) para mensurar o engajamento emocional, e os estudos de Voisin et al. (2017) e de Buhs et al. (2018), que utilizaram a "School Bonding Scale" para avaliar 
o engajamento dos alunos. Conforme destacam Hazel et al. (2014), as escalas de engajamento têm sido criticadas por incluir correlatos de engajamento como facilitadores ambientais (atitude dos pares, supervisão parental) e indicadores do engajamento (conclusão de disciplina e competências acadêmicas). Os constructos correlatos ao engajamento escolar e a justaposição de termos relacionados, que podem ou não compartilhar o mesmo significado, ainda são um desafio para a pesquisa na área. Alguns termos, como "school bonding", "school attachment", "school commitment" e "motivation", já foram reconhecidos e relatados na literatura sobre o engajamento escolar (Jimerson et al., 2003); no entanto, a diferenciação deles e a sua preeminência ainda não foram amplamente destacadas pela literatura atual. Esforços para contrastar os constructos correlatos são encontrados em estudos como o de Martin et al. (2017), que buscou diferenciar a motivação do engajamento. A motivação é um constructo frequentemente associado ao engajamento devido a este ser visto como um mediador entre a motivação e o desempenho escolar (Reeve, 2012). 0 estudo de Martin et al. (2017) encontrou evidências de que existe um relacionamento cíclico entre motivação e engajamento, sendo a motivação um fator impulsionador para um engajamento subsequente, e este, por sua vez, também age como um catalisador da motivação futura. Dessa forma, entender as semelhanças e diferenças entre os constructos correlatos ao engajamento é crucial para o avanço na área.

No que diz respeito à temática dos estudos, $30 \%$ deles são relativos ao tema suporte dos pais, professores e pares. Tal prevalência está em consonância com os estudos da última década, como ressaltam Veiga et al. (2012). Essas publicações apontam para uma preocupação dos pesquisadores em compreender como as variáveis contextuais operam no engajamento (De Laet et al., 2015; Furlong \& Christenson, 2008; Konold et al., 2018; Lam et al., 2012; Yang et al., 2017), pois ao entender o contexto é possível criar programas de intervenção para desenvolver o engajamento. Como variáveis contextuais podemos relatar o formato do currículo escolar e a supervisão dos pais (Hazel et al., 2014), as atitudes dos pares, no sentido de reforçar ou repelir comportamentos, e a relação dos alunos com os professores, bem como a forma instrucional que estes adotam (Ryan et al., 2019). As intervenções para o fomento do engajamento têm sido direcionadas para as variáveis contextuais, como o Programa de Aprendizagem Socioemocional (Social-Emotional Learning Programs - SEL), que visa a socialização positiva e o apoio social (Ryan et al., 2019).

O segundo tema mais encontrado foi saúde mental, em $10 \%$ dos estudos. As publicações nessa área seguem a linha da Psicologia Positiva e pesquisas têm indicado o engajamento escolar como um potencial fator de proteção contra comportamentos psicossociais negativos, como uso de drogas, álcool e comportamento agressivo; também relacionam maior grau de engajamento a resultados de altos níveis de bem-estar e satisfação com a vida (Carter et al., 2007). Alguns temas apresentaram um número reduzido de pesquisas, tais como gênero e LGBT, bullying, e necessidades educativas especiais, o que revela que este ainda é um campo fértil de pesquisa, dada a complexidade do constructo, que tangencia diversos assuntos de interesse dos pesquisadores das áreas de Educação e Psicologia. 
Por fim, percebe-se que somente 48 estudos analisados foram realizados fora do eixo América do Norte/Europa, evidenciando que o campo de estudo desse constructo é amplamente pesquisado em países desenvolvidos e que a preocupação com a mensuração do constructo é recorrente nesses locais. Estudos em outros continentes e culturas são importantes porque o engajamento escolar pode ser diferentemente impactado conforme o contexto. Por exemplo, no estudo de Bear et al. (2018) analisou-se a relação entre a percepção do clima escolar e o engajamento em estudantes americanos e chineses. Os pesquisadores observaram que embora os estudantes chineses tendessem a perceber o clima escolar de suas escolas como mais positivo, apenas no caso dos estudantes americanos houve relação entre clima escolar e engajamento. Além disso, outro fator a se considerar é o estudo do engajamento escolar em países pobres. Yang et al. (2018) observaram que em famílias com dificuldades materiais o engajamento escolar foi um mediador do índice de repetência escolar e argumentaram que é importante ter intervenções para populações de baixa renda que considerem tanto auxílios em relação à pobreza material, quanto tentativas de aumentar o engajamento escolar nessas populações. Assim sendo, estudos em diferentes países e culturas tornam-se relevantes, pois nem sempre as relações entre o engajamento escolar e outras variáveis são as mesmas em diferentes culturas e contextos socioeconômicos.

Pode-se dizer que a presente revisão sistemática, ao mapear a produção sobre o engajamento escolar nos últimos anos, contribui para a detecção das áreas de maior avanço nas pesquisas e ajuda na sugestão de estudos futuros. Por exemplo, é notório o grande volume de estudos sobre o engajamento escolar em países desenvolvidos; no entanto, ainda são necessários mais estudos em culturas diferentes e em países pobres para avaliar se as relações entre o engajamento escolar, o desempenho e o abandono escolar são as mesmas nesses países. Além disso, como pontuado acima, é importante que se desenvolvam instrumentos para avaliar o engajamento nos anos iniciais do ensino fundamental e estudos com crianças dessa faixa etária para que se possa compreender melhor a relação entre o engajamento e o desempenho escolar ao longo do tempo. Por fim, o pequeno número de estudos experimentais e quasi-experimentais indica a necessidade de mais estudos com estes delineamentos devido à sua importância para a avaliação e desenvolvimento de intervenções que visem melhorar o engajamento escolar.

Uma limitação do presente estudo é referente ao critério de inclusão. Admitiram-se publicações na modalidade artigo científico, não incluindo teses, dissertações e relatos de pesquisas em congressos. Apesar dessa restrição, acredita-se que a não inclusão desses demais gêneros não enviesa os resultados dessa revisão sistemática porque, geralmente, teses, dissertações e trabalhos apresentados em congressos tendem a ser publicados posteriormente como artigos em revistas científicas. Outra limitação refere-se à necessidade de unir uma diversidade de temas em categorias analíticas, como suporte dos pais, pares e professores. A tarefa de juntar as variáveis em categorias analíticas fez-se necessária devido ao amplo número de temas investigados e associados ao engajamento escolar. No entanto, a fim de analisar os temas que constituem determinada categoria analítica e sua relação com o engajamento, seria necessário desmembrar as categorias analíticas. 


\section{CONSIDERAÇÕES FINAIS}

Nas últimas duas décadas o conceito e a dimensionalidade do engajamento eram foco de discussão nos estudos sobre engajamento escolar (Christenson et al., 2012). Apesar de ser necessária a discussão a respeito de modelos teóricos do engajamento, o interesse em aspectos contextuais e individuais do constructo foi recorrente nessa revisão sistemática. Ressalta-se que um dos aspectos contextuais mais estudados atualmente refere-se ao suporte dos pais, professores e pares (De Laet et al., 2015; Portilla et al., 2014; Zeldin et al., 2018), sendo estes importantes componentes para mudanças no contexto e no engajamento escolar, uma vez que o engajamento é responsivo ao contexto (Konold et al., 2018).

0 foco recente do engajamento escolar é o entendimento da relação desse constructo com o desempenho acadêmico. Uma boa parte dos estudos que avaliam essa relação são realizados com crianças mais velhas e adolescentes e somente um número reduzido de artigos analisaram o engajamento em crianças mais novas, de 7 a 12 anos (p. ex., Leonard \& Gudiño, 2016; Orkibi \& Tuaf, 2017). A baixa frequência surpreende, uma vez que o constructo é tido como uma ferramenta para modificar o contexto escolar e a infância é vista como um período sensível para a aquisição de hábitos escolares positivos (rotina de estudo, adesão às regras, estratégias de aprendizagem) que podem afetar o desempenho acadêmico.

Os resultados dessa revisão apresentam um panorama do constructo nos últimos cinco anos, demonstrando aumento de estudos na área que abarca diversos temas. Acrescenta-se a necessidade de mais estudos experimentais e quasi-experimentais, pois estes são importantes para avaliar o sucesso de intervenções que visem melhorar o engajamento escolar.

Por fim, considerando-se o contexto brasileiro, percebe-se escassez de estudos sobre o tema, sendo de suma importância o desenvolvimento de instrumentos para avaliar o engajamento, bem como estudos que avaliem a relação entre o engajamento escolar e outras variáveis pertinentes ao contexto escolar considerando a realidade brasileira e internacional.

\section{REFERÊNCIAS}

Appleton, J. J., Christenson, S. L., \& Furlong, M. J. (2008). Student engagement with school: Critical conceptual and methodological issues of the construct. Psychology in the Schools, 45(5), 369-386. https://doi.org/10.1002/ pits.20303

Appleton, J. J., Christenson, S. L., Kim, D., \& Reschly, A. L. (2006). Measuring cognitive and psychological engagement: Validation of the student engagement instrument. Journal of School Psychology, 44(5), 427-445. https://doi.org/10.1016/j. jsp.2006.04.002

Arastaman, G. (2006). Ankaraili lise birinci sinif öğrencilerinin okula bağlilik durumlarina ilişkin öğrenci, öğretmen ve yöneticilerin görüşleri (Yayınlanmamış Yüksek Lisans Tezi). Ankara Üniversitesi, Ankara, Turkey. 
Awang-Hashim, R., Azlina, H., \& Sani, A. M. (2008). A confirmatory factor analysis of a newly integrated multidimensional school engagement scale. Malaysian Journal of Learning \& Instruction, 5, 21-40. https://doi.org/10.32890/ mjli2008.5.0.7595

Baker, S. K., Nelson, N. J., Stoolmiller, M., Paine, P. K., Turtura, J., Crone, D., \& Fien, H. (2018). Intervening with struggling readers in seventh grade: Impact evidence from six school districts. Journal of Research on Educational Effectiveness, 11(4), 479-506. https://doi.org/10.1080/19345747.2018.1472357

Bear, G. G., Yang, C., Chen, D., He, X., Xie, J.S., \& Huang, X. (2018). Differences in school climate and student engagement in China and the United States. School Psychology Quarterly, 33(2), 323-335. https://doi.org/10.1037/ spq0000247

Bear, G., Yang, C., Mantz, L., Pasipanodya, E., Hearn, S., \& Boyer, D. (2016). Technical manual for Delaware school survey: Scales of school climate, bullying victimization, student engagement, and positive, punitive, and social emotional learning techniques. Delaware Positive Behavior Support (DE-PBS) and School Climate Transformation Projects. Disponível em http://wh1.oet.udel.edu/pbs/wp-content/ uploads/2011/12/Delaware-School-Survey-Technical-Manual-Fall-2016.pdf

Brutsaert, H. (1993). School, gezin en welbevinden: Zesdeklassers en hun sociale omgeving. Leuven: Garant.

Buhs, E. S., Koziol, N. A., Rudasill, K. M., \& Crockett, L. J. (2018). Early temperament and middle school engagement: School social relationships as mediating processes. Journal of Educational Psychology, 110(3), 338-354. https://doi. org/10.1037/edu0000224

Çakar, F. S., \& Karataş, Z. (2014, April). Ergenlerin okula bağlanmalarının yordayıcıları olarak benlik saygıs, okul öfkesi ve yaşam doyumu. Poster session presented at 5th International Conference on New Trends in Education and Their Implications, Antalya, Turkey.

Can, S. (2008). Primary II. Examining students' level of commitment to the school stage, according to some variables (Unpublished master's thesis). Ege University Institute of Social Sciences, İzmir, Turkey.

Carter, M., McGee, R., Taylor, B., \& Williams, S. (2007). Health outcomes in adolescence: Associations with family, friends and school engagement. Journal of Adolescence, 30(1), 51-62. https://doi.org/10.1016/j.adolescence.2005.04.002

Çengel, M., Totan, T., \& Çöğmen, S. (2017). Okula bağlılık ölçeğinin türkçeye uyarlanması. Abant İzzet Baysal Üniversitesi Eğitim Fakültesi Dergisi, 17(4), 1820-1837. https://doi.org/10.17240/aibuefd.2017.17.32772-363966

Cho, E., Toste, J. R., Lee, M., \& Ju, U. (2018). Motivational predictors of struggling readers' reading comprehension: The effects of mindset, achievement goals, and engagement. Reading and Writing, 32(5), 1219-1242. https://doi. org/10.1007/s11145-018-9908-8

Christenson, S. L., Reschly, A. L., \& Wylie, C. (2012). Handbook of research on student engagement. Springer.

Coelho, C. C. A., \& Dell'Aglio, D. D. (2018). Engajamento escolar: Efeito do suporte dos pais, professores e pares na adolescência. Psicologia Escolar e Educacional, 22(3), 621-629. https://doi.org/10.1590/2175-35392018038539 
De Laet, S., Colpin, H., Vervoort, E., Doumen, S., Van Leeuwen, K. V., Goossens, L., \& Verschueren, K. (2015). Developmental trajectories of children's behavioral engagement in late elementary school: Both teachers and peers matter. Developmental Psychology, 51(9), 1292-1306. https://doi.org/10.1037/a0039478

Eccles, J. S., Midgley, C., Wigfield, A., Buchanan, C. M., Reuman, D., Flanagan, C., \& Mac Iver, D. (1993). Development during adolescence: The impact of stageenvironment fit on adolescents' experiences in schools and families. American Psychologist, 48(2), 90-101. https://doi.org/10.1037/0003-066X.48.2.90

Finn, J. D. (1989). Withdrawing from school. Review of Educational Research, 59(2), 117-142. https://doi.org/10.3102/00346543059002117

Finn, J. D., \& Rock, D. A. (1997). Academic success among students at risk for school failure. Journal of Applied Psychology, 82(2), 221-234. https://doi. org/10.1037/0021-9010.82.2.221

Fleming, C. B., Catalano, R. F., Haggerty, K. P., \& Abbott, R. D. (2010). Relationships between level and change in family, school, and peer factors during two periods of adolescence and problem behavior at age 19. Journal of Youth and Adolescence, 39(6), 670-682. https://doi.org/10.1007/s10964-010-9526-5

Fonsêca, P. N., Lopes, B. J., Palitot, R. M., Estanislau, A. M., Couto, R. N., \& Coelho, G. L. H. (2016). Engajamento escolar: Explicação a partir dos valores humanos. Psicologia Escolar e Educacional, 20(3), 611-620. https://doi. org/10.1590/2175-3539201502031061

Fredricks, J. A., Blumenfeld, P. C., \& Paris, A. H. (2004). School engagement: Potential of the concept, state of the evidence. Review of Educational Research, 74(1), 59-109. https://doi.org/10.3102/00346543074001059

Fredricks, J. A., Blumenfeld, P., Friedel, J., \& Paris, A. (2005). School engagement. In K. A. Moore \& L. H. Lippman (Eds.), What do children need to flourish?: Conceptualizing and measuring indicators of positive development (pp. 305-321). Springer.

Fredricks, J. A., College, C., Blumenfeld, P., Friedel, J., \& Paris, A. (2003, March). School engagement. Paper presented at the meeting of The Indicators of Positive Development Conference, Washington, DC. Disponível em https://www. childtrends.org/wp-content/uploads/2013/05/Child_Trends-2003_03_12_PD_ PDConfFBFP.pdf

Furlong, M., \& Christenson, S. (2008). Engaging students at school and with learning: A relevant construct for all students. Psychology in the Schools, 45(5), 365-368. https://doi.org/10.1002/pits.20302

Furrer, C., \& Skinner, E. (2003). Sense of relatedness as a factor in children's academic engagement and performance. Journal of Educational Psychology, 95(1), 148-162. https://doi.org/10.1037/0022-0663.95.1.148

Gavidia-Payne, S., Denny, B., Davis, K., Francis, A., \& Jackson, M. (2015). Children's self-concept: Parental school engagement and student-teacher relationships in rural and urban Australia. Social Psychology of Education, 18(1), 121-136. https://doi.org/10.1007/s11218-014-9277-3

Gouveia, R. S. V. (2009). Engajamento escolar e depressão: Um estudo correlacional com crianças e adolescentes (Tese de doutoramento não publicada). Universidade Federal da Paraíba, Paraíba, Brasil.

Guo, Y., Sun, S., Breit-Smith, A., Morrison, F., \& Connor, C. (2015). Behavioral engagement and reading achievement in elementary-school-age children: 
A longitudinal cross-lagged analysis. Journal of Educational Psychology, 107(2), 332-347. https://doi.org/10.1037/a0037638

Hakanen, J., Bakker, A. B., \& Schaufeli, W. (2006). Burnout and work engagement among teachers. Journal of School Psychology, 43(6), 495-513. https://doi.org/10.1016/j.jsp.2005.11.001

Hazel, C. E., Vazirabadi, G. E., Albanes, J., \& Gallagher, J. (2014). Evidence of convergent and discriminant validity of the student school engagement measure. Psychological Assessment, 26(3), 806-814. https://doi.org/10.1037/ a0036277

Hernandez, L. (2012). Relations entre pairs et mobilisation scolaire d'adolescents de 14 à 16 ans: Entre richesse et pression du groupe: Le rôle médiateur de la valeur accordée à l'école (Thèse de doctorat). Université Toulouse le Mirail, Toulouse, France. Disponível em https://tel.archives-ouvertes.fr/tel-00813639/ document

Hidiroğlu, F. M. (2014). The role of perceived classroom goal structures, selfefficacy, and the student engagement in seventh grade students'science achievement (Unpublished master's thesis). Middle East Technical University, Ankara, Turkey.

Holst, B., Weber, J., Bear, G. G., \& Lisboa, C. (2016). Adaptación transcultural y validación del contenido del Delaware School Climate Survey-Student (DSCS-S) en Brasil. Revista Electrónica de Investigación y Evaluación Educativa, 22(2), 1-12. https://doi.org/10.7203/relieve.22.2.6459

Hughes, J. N., \& Kwok, O.-M. (2006). Classroom engagement mediates the effect of teacher-student support on elementary students' peer acceptance: A prospective analysis. Journal of School Psychology, 43(6), 465-480. https://doi. org/10.1016/j.jsp.2005.10.001

Jimerson, S., Campos, E., \& Greif, J. L. (2003). Toward an understanding of definitions and measures of school engagement and related terms. The California School Psychologist, 8(1),7-27. https://doi.org/10.1007/BF03340893

Justi, F. R. R., Justi, C. N. G., Quirin, M. A. A., \& Silveira, M. E. (2019). Engajamento escolar e compreensão de leitura. In S. R. K. Guimarães \& F. V. de Paula (Orgs.), Compreensão da leitura: Processos cognitivos e estratégias de ensino (pp. 215-229). Vetor.

Kim, J. S., Hemphill, L., Troyer, M., Thomson, J. M., Jones, S. M., LaRusso, M. D., \& Donovan, S. (2017). Engaging struggling adolescent readers to improve reading skills. Reading Research Quarterly, 52(3), 357-382. https://doi.org/10.1002/rrq.171

Konold, T., Cornell, D., Jia, Y., \& Malone, M. (2018). School climate, student engagement, and academic achievement: A latent variable, multilevel multi-informant examination. AERA Open, 4(4), 1-17. https://doi. org/10.1177/2332858418815661

Lam, S., Jimerson, S., Kikas, E., Cefai, C., Veiga, F. H., Nelson, B., ... Zollneritsch, J. (2012). Do girls and boys perceive themselves as equally engaged in school? The results of an international study from 12 countries. Journal of School Psychology, 50(1), 77-94. https://doi.org/10.1016/j.jsp.2011.07.004

Leonard, S. S., \& Gudiño, O. G. (2016). Academic and mental health outcomes of youth placed in out-of-home care: The role of school stability and engagement. Child \& Youth Care Forum, 45(6), 807-827. https://doi.org/10.1007/ s10566-016-9357-y

Li, Y., \& Lerner, R. M. (2013). Interrelations of behavioral, emotional, 
and cognitive school engagement in high school students. Journal of Youth and Adolescence, 42(1), 20-32. https://doi.org/10.1007/s10964-012-9857-5

Lovelace, M. D., Reschly, A. L., \& Appleton, J. J. (2018). Beyond school records: The value of cognitive and affective engagement in predicting dropout and on-time graduation. Professional School Counseling, 21(1), 1096-2409. https://doi.org/10.5330/1096-2409-21.1.70

Mameli, C., \& Passini, S. (2017). Measuring four-dimensional engagement in school: A validation of the student engagement scale and of the agentic engagement scale. TPM - Testing, Psychometrics, Methodology in Applied Psychology, 24(4), 527-541. https://doi.org/10.4473/TPM24.4.4

Marques, S. C., Lopez, S. J., Fontaine, A. M., Coimbra, S., \& Mitchell, J. (2015). How much hope is enough? Levels of hope and students' psychological and school functioning. Psychology in the Schools, 52(4), 325-334. https://doi.org/10.1002/ pits.21833

Martin, A. J., Ginns, P., \& Papworth, B. (2017). Motivation and engagement: Same or different? Does it matter? Learning and Individual Differences, 55, 150-162. https://doi.org/10.1016/j.lindif.2017.03.013

Maslach, C., \& Jackson, S. E. (1981). The measurement of experienced burnout. Journal of Occupational Behaviour, 2(2), 99-113. https://doi.org/10.1002/ job.4030020205

Orkibi, H., \& Tuaf, H. (2017). School engagement mediates well-being differences in students attending specialized versus regular classes. The Journal of Educational Research, 110(6), 675-682. https://doi.org/10.1080/00220671.2016.117 5408

Portilla, X. A., Ballard, P. J., Adler, N. E., Boyce, W. T., \& Obradović, J. (2014). An integrative view of school functioning: Transactions between self-regulation, school engagement, and teacher-child relationship quality. Child Development, 85(5), 1915-1931. https://doi.org/10.1111/cdev.12259

Ramos-Díaz, E., Rodríguez-Fernández, A., \& Revuelta, L. (2016). Validation of the Spanish version of the school engagement measure (SEM). The Spanish Journal of Psychology, 19(86). https://doi.org/10.1017/sjp.2016.94

Reeve,J. (2012). A self-determination theory perspective on student engagement. In L. S. Christenson, A. L. Reschly, \& C. Wylie (Eds.), Handbook of research on student engagement (pp. 149-171). Springer.

Reeve, J., \& Ching-Mei, T. (2011). Agency as a fourth aspect of students' engagement during learning activities. Contemporary Educational Psychology, 36(4), 257-267. https://doi.org/10.1016/j.cedpsych.2011.05.002

Rodrigues, H., \& Nascimento, I. (2016). Influência(s) do enriquecimento curricular no desenvolvimento vocacional e envolvimento escolar dos alunos. Revista Brasileira de Orientação Profissional, 17(2), 245-256.

Rodriguez, R. J., \& Elbaum, B. (2014). The role of student-teacher ratio in parents' perceptions of schools' engagement efforts. The Journal of Educational Research, 107(1), 69-80. https://doi.org/10.1080/00220671.2012.753856

Rola, A. S. (2012). Envolvimento dos alunos na escola: Um estudo com alunos do $7 .^{\circ}$ e do $9 .^{\circ}$ ano (Dissertação de mestrado). Universidade de Lisboa, 
Lisboa, Portugal. Disponível em http://repositorio.ul.pt/bitstream/10451/8230/1/ ulfpie043250_tm.pdf

Ryan, A. M., North, E. A., \& Ferguson, S. (2019). Peers and engagement. In J. A. Fredricks, A. L. Reschly, \& S. L. Christenson (Eds.), Handbook of student engagement interventions

(pp.73-85). Londres, Inglaterra: Academic Press. https://doi.org/10.1016/ b978-0-12-813413-9.00006-1

Salanova, M., Bresó, E., \& Schaufeli, W. B. (2005). Hacia un modelo espiral de las creencias de eficacia en el estudio del burnout y del engagement. Ansiedad y Estrés, 11(2-3), 215-231.

Salanova, M., Schaufeli, W. B., Llorens, S., Peiró, J. M., \& Grau, R. (2000). Desde el "burnout" al "engagement”: ¿Una nueva perspectiva? Revista de Psicología del Trabajo y de las Organizaciones, 16(2), 117-134.

Salmela-Aro, K., \& Upadyaya, K. (2012). The schoolwork engagement inventory: Energy, dedication, and absorption (EDA). European Journal of Psychological Assessment, 28(1), 60-67. https://doi.org/10.1027/1015-5759/a000091

Schaufeli, W. B., Martínez, I. M., Pinto, A. M., Salanova, M., \& Bakker, A. B. (2002). Burnout and engagement in university students: A crossnational study. Journal of Cross-Cultural Psychology, 33(5), 464-481. https://doi. org/10.1177/0022022102033005003

Schaufeli, W. B., Salanova, M., Gonzalez-Romá, V., \& Bakker, A. B. (2002). The measurement of engagement and burnout: A two sample confirmatory factor analytic approach. Journal of Happiness Studies, 3(1), 71-92. https://doi.org/10.1023/ A1015630930326

Silveira, M. E., \& Justi, F. R. R. (2018). Engajamento escolar: Adaptação e evidências de validade da escala EAE-E4D. Psicologia: Teoria e Prática, 20(1), 110-125. https://doi.org/10.5935/1980-6906/psicologia.v20n1p110-125

Skinner, E., Furrer, C., Marchand, G., \& Kindermann, T. (2008). Engagement and disaffection in the classroom: Part of a larger motivational dynamic? Journal of Educational Psychology, 100(4), 765-781. https://doi.org/10.1037/a0012840

Skinner, E., Zimmer-Gembeck, M., Connell, J., Eccles, J., \& Wellborn, J. (1998). Individual differences and the development of perceived control. Monographs of the Society for Research in Child Development, 63(2-3), 1-231. https:// doi.org/10.2307/1166220

Stelko-Pereira, A. C., \& Williams, L. C. A. (2016). Evaluation of a Brazilian school violence prevention program (Violência nota zero). Pensamiento Psicológico, 14(1), 63-76. https://doi.org/10.11144/Javerianacali.PPSI14-1.ebsv

Upadyaya, K., \& Salmela-Aro, K. (2013). Development of school engagement in association with academic success and well-being in varying social contexts: A review of empirical research. European Psychologist, 18(2), 136-147. http://doi.org/10.1027/1016-9040/a000143

Uzzaman, M. A., \& Karim, A. K. M. R. (2016). The psychometric properties of the school engagement scale in Bangladeshi culture. Journal of the Indian Academy of Applied Psychology, 42(1), 143-153.

Valle, J. E., Stelko-Pereira, A. C., Peixoto, E. M., \& Williams, L. C. A. (2018). Influence of bullying and teacher-student relationship on school engagement: Analysis of an explanatory model. Estudos de Psicologia, 35(4), 411-420. https://doi. org/10.1590/1982-02752018000400008 
Valle, J. E., Stelko-Pereira, A. C., Sá, L. G. C., \& Williams, L. C. A. (2015). Bullying, vitimização por funcionários e depressão: Relações com o engajamento emocional escolar. Psicologia Escolar e Educacional, 19(3), 463-473.

https://doi.org/10.1590/2175-3539/2015/0193872

Veiga, F. H. (2013). Envolvimento dos alunos na escola: Elaboração de uma nova escala de avaliação. International Journal of Developmental and Educational Psychology, 1(1), 441-450.

Veiga, F., Galvão, D., Almeida, A., Carvalho, C., Janeiro, I., Nogueira, J., ... Pereira, T. (2012, November). Student's engagement in school: A literature review. Paper presented at the meeting of the 5th International Conference of Education, Madrid, Spain.

Voisin, D. R., Elsaesser, C., Kim, D. H., Patel, S., \& Cantara, A. (2016). The relationship between family stress and behavioral health among African American adolescents. Journal of Child and Family Studies, 25(7), 2201-2210. https://doi. org/10.1007/s10826-016-0402-0

Voisin, D. R., Harty, J., Kim, D. H., Elsaesser, C., \& Takahashi, L. M. (2017). Assessing the relationship between parental influences and wellbeing among low income African American adolescents in Chicago. Child \& Youth Care Forum, 46(2), 223-242. https://doi.org/10.1007/s10566-016-9373-y

Wang, M., Chow, A., Hofkens, T., \& Salmela-Aro, K. (2015). The trajectories of student emotional engagement and school burnout with academic and psychological development: Findings from Finnish adolescents. Learning and Instruction, 36, 57-65. https://doi.org/10.1016/j.learninstruc.2014.11.004

Wang, M., T., Willett, J., B., \& Eccles, J. S. (2011). The assessment of school engagement: Examining dimensionality and measurement invariance by gender and race/ethnicity. Journal of School Psychology, 49(4), 465-480. https://doi. org/10.1016/j.jsp.2011.04.001

Yang, G., Badri, M., Al Rashedi, A., Almazroui, K., Qalyoubi, R., \& Nai, P. (2017). The effects of classroom and school environments on student engagement: The case of high school students in Abu Dhabi public schools. Compare: A Journal of Comparative and International Education, 47(2), 223-239. https://doi.org/10.1080/030 57925.2016.1230833

Yang, M.-Y., Chen, Z., Rhodes, J. L. F., \& Orooji, M. (2018). A longitudinal study on risk factors of grade retention among elementary school students using a multilevel analysis: Focusing on material hardship and lack of school engagement. Children and Youth Services Review, 88(1), 25-32. https://doi. org/10.1016/j.childyouth.2018.02.043

Yusof, N., Ang, R. P., \& Oei, T. P. S. (2017). The psychometric properties of the school engagement measure in adolescents in Singapore. Journal of Psychoeducational Assessment, 35(5), 521-533. https://doi. org/10.1177/0734282916639441

Zeldin, S., Gauley, J. S., Barringer, A., \& Chapa, B. (2018). How high schools become empowering communities: A mixed method explanatory inquiry into youth-adult partnership and school engagement. American Journal of Community Psychology, 61(3-4), 358-371. https://doi.org/10.1002/ajcp.12231

Zhang, W., Du, D., Zhen, S., Warren, A. E. A., Lerner, R. M., \& Phelps, E. (2011). Belief systems and positive youth development among Chinese and American youth. In A. E. A. Warren, R. M. Lerner, \& E. Phelps (Eds.), Thriving and spirituality 
among youth: Research perspectives and future possibilities (pp. 309-331). John Wiley \& Sons, Inc.

Zhao, W., Song, Y., Zhao, Q., \& Zhang, R. (2019). The effect of teacher support on primary school students' reading engagement: The mediating role of reading interest and chinese academic self-concept. Educational Psychology, 39(2), 236-253. https://doi.org/10.1080/01443410.2018.1497146

Informação dos autores:

i Universidade Federal de Juiz de Fora, Programa de PósGraduação em Psicologia, Brasil. https://orcid.org/0000-0001-6270-7288

ii Universidade Federal de Juiz de Fora, Programa de PósGraduação em Psicologia, Brasil. https://orcid.org/0000-0003-4979-7623

iii Universidade de Trás-os-Montes e Alto Douro, Portugal. https: //orcid.org/0000-0002-8501-5169

iv Universidade Federal de Juiz de Fora, Programa de PósGraduação em Psicologia, Brasil.

https://orcid.org/0000-0001-7107-1672

Toda a correspondência relativa a este artigo deve ser enviada para:

Juliana Campos Schmitt

Travessa Padre João Batista Reus, n. ${ }^{\circ} 23$, apartamento 201

Bairro: Centro, Juiz de Fora - Minas Gerais - Brasil

CP: 36036-030

julianaschmittufjf@hotmail.com

Recebido em 26 de junho de 2019

Aceite para publicação em 20 de abril de 2020 


\title{
An overview of school engagement: A systematic review
}

\begin{abstract}
The purpose of this study was to systematically review the publications on school engagement in the SciELO, PsycINFO and ERIC databases with the following descriptors: "school engagement", "engajamento escolar" and "envolvimento escolar". The studies that met the inclusion criteria were selected: (a) articles with the abovementioned descriptors in the title, abstract or keywords; (b) studies published in the scientific article modality and (c) in the period from 2014 to 2018. As exclusion criteria: (a) articles focusing on other topics, (b) not fully available and (c) duplicates. There were 410 studies and 203 selected. Most of the studies are correlational and the production on engagement is concentrated on the North America/Europe axis. The engagement was treated in most of the studies as a three-dimensional construct and 35 scales were found to assess engagement. Further experimental and quasi-experimental studies are necessary due to their importance for the evaluation and development of interventions aimed at improving school engagement, and also studies that evaluate the relationship between school engagement and other relevant variables to the school context.
\end{abstract}

Keywords: School engagement; School involvement; Engagement scales 


\section{Un aperçu de l'engagement scolaire: Une révision systématique}

\section{RÉSUMÉ}

Lobjectif de cette étude était de faire une révision systématique des publications sur l'engagement scolaire, dans les bases de données SciELO, PsycINFO et ERIC, à partir des descripteurs suivants: "school engagement", "engajamento escolar" et "envolvimento escolar". Ainsi, les études ont été sélectionnées selon les critères d'inclusion: (a) articles dont les descripteurs sont mentionnés dans le titre, dans le résumé ou dans les motsclés; (b) études publiées sous la modalité d'article scientifique et (c) avec parution entre 2014 et 2018. Et selon les critères d'exclusion: (a) articles traitant d'autres thèmes, (b) juste partiellement disponibles et (c) en double. À partir de ces critères, 203 études ont été sélectionnées entre les 410 études trouvées. Entre les sélectionnées, la plupart des études sont corrélationnelles et la production sur le thème de l'engagement est concentrée sur l'axe Amérique du Nord/Europe. L'engagement a été traité dans la plupart de ces études comme une construction tridimensionnelle et 35 échelles évaluant l'engagement ont été trouvées. D'autres études expérimentales et quasi expérimentales sont nécessaires, en raison de leur importance pour l'évaluation et le développement d'interventions visant à améliorer l'engagement scolaire, ainsi que des études qui évaluent la relation entre l'engagement scolaire et d'autres variables pertinentes au contexte scolaire.

Mots-clés: Engagement scolaire; Implication scolaire; Échelles d'engagement 